\title{
A FUNÇÃO EXTRAFISCAL DO TRIBUTO ENQUANTO VETOR DAS POLÍTICAS PÚBLICAS: A JUVENTUDE BRASILEIRA NA AGENDA POLÍTICA
}

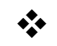 \\ Fabiano Rodrigo Dupont \\ Universidade de Santa Cruz do Sul - UNISC - Brasil \\ Rodrigo Cristiano Diehl \\ Universidade de Santa Cruz do Sul-UNISC - Brasil
}

\begin{abstract}
Resumo
O objetivo com o presente estudo é analisar a função extrafiscal do tributo enquanto vetor das políticas públicas voltadas para a garantia dos direitos fundamentais da juventude brasileira. Diante desse cenário, são pontuados e discutidos o atual papel do poder público na construção de políticas públicas efetivadoras dos direitos da juventude. Cotejados estes aspectos, apresenta-se a finalidade extrafiscal da norma tributária como mecanismo de implementação de políticas públicas. E a partir disso, analisa-se a possibilidade e o desenvolvimento de políticas públicas com o intuito da inclusão social de jovens no cenário brasileiro. Para tal feito, utiliza-se o método hipotético-dedutivo, através de levantamento bibliográfico.
\end{abstract}

Palavras-chave: agenda política; direitos fundamentais; função extrafiscal; juventude; políticas púbicas.

\section{Considerações Iniciais}

A juventude brasileira, especialmente se considerado os últimos dez anos, tem ocupado cada vez mais espaço na agenda pública com a discussão e implementação de políticas públicas com a finalidade da proteção social, inserção profissional e o incentivo a sua participação política. Colaborando com essa inserção em agosto de 2013 foi editado o Estatuto da Juventude, que findou com um processo de quase dez anos de lutas e discussões por garantias de direitos dessa porção da população.

Neste contexto, o objetivo do presente estudo é a realização de uma análise sistemática da utilização da função extrafiscal da norma tributária como mecanismos de 
implementação de políticas públicas com base no agir público e na consolidação de direitos fundamentais da juventude brasileira. Para tanto, dividiu-se o trabalho em três momentos, o primeiro deles discorre-se sobre o papel do poder público na construção de políticas públicas efetivadoras dos direitos da juventude brasileira, partindo do pressuposto que o mundo encontra-se em constante transformação e os jovens da atualidade vivenciam problemas e incertezas de seu tempo.

Assentados estes aspectos, migra-se para o estudo da finalidade extrafiscal da norma tributária como mecanismo de implementação de políticas públicas, onde o objetivo principal é a sua utilização na redistribuição de rendas e de terras, a defesa da indústria nacional, a orientação de certos investimentos em setores estratégicos de produção mas, principalmente no incentivo a jovens que carecem de ações efetivas de cidadania.

E dessa forma, conclui-se o trabalho analisando a utilização da extrafiscalidade tributária enquanto política pública de desenvolvimento e inclusão social de jovens no atual mundo globalizado, uma vez que diante do cenário exclusão social, tem-se uma parcela da juventude brasileira que se vê as margens do sistema de proteção dos direitos e garantias fundamentais.

Dessa maneira, para a construção do presente estudo utilizar-se-á o método hipotético dedutivo como metodologia de abordagem, já que consiste na adoção tanto do procedimento racional quanto do procedimento experimental. E assim, a pesquisa desenvolver-se-á sobre preposições hipotéticas que se acredita serem viáveis. No que concerne às técnicas, o aprofundamento do estudo será realizado com base em pesquisa bibliográfica, baseada em dados secundários, como por exemplo, livro, artigos científicos, publicações avulsas, revistas e períodos qualificados dentro da temática proposta.

\section{O papel do poder público na construção de políticas públicas efetivadoras dos direitos da juventude brasileira}

Em meio às inúmeras transformações na sociedade, sejam elas de caráter econômico, político ou social, demarcam a era contemporânea trazida pelo século XXI, onde o conceito de criança, adolescentes e jovens adquire novos significados e uma determinada dimensão social até então não conhecido no mundo ocidental. A partir desse momento deixam de ser unicamente um objeto de interesse, preocupação e ação no âmbito privado da família e da igreja para tornar-se uma questão de cunho social, sendo assim, de competência não só do Estado, mas também de toda a sociedade.

Barbarói, Santa Cruz do Sul, Edição Especial n.44, p.<4-17>, jul./dez. 2015 
Deste modo, crianças, adolescentes e jovens deixam de ocupar uma posição secundária tanto na família quanto na sociedade e passam a serem compreendidos como um valioso patrimônio da nação, a chave para o futuro, sendo assim nas palavras de Rizzini (2011, p. 24, grifo original) “um ser em formação - 'dúctil e moldável' - que tanto pode ser transformado em 'homem de bem' (elemento útil para o progresso da nação) ou num ‘degenerado' (um vicioso inútil a pesar nos cofres públicos)”.

Nesse sentido, ao se buscar na literatura histórica referências sobre o espaço que era destinado a esses indivíduos na sociedade brasileira, verifica-se incontestavelmente que a criança, o adolescente e o jovem que mais aparecia era aquele que, para os olhos da elite do século XX, desprovido de proteção por parte do Estado e, portanto necessitavam ser corrigidos ou reeducados. Na exata definição de Rizzini (2011, p. 45, grifo original) eram os “'expostos', os 'orphaosinhos', os 'pobres meninos abandonados', as 'creanças criminosas' os 'menores delinquentes' e assim por diante. Onde constava algo relativo à infância ou à juventude, lá estava implícita a ideia de periculosidade”.

Todavia, a partir da segunda metade da década de 1990, o tema da juventude inicia o sua trajetória de projeção e complexidade diante do espaço público brasileiro. E assim sendo, ao mesmo tempo em que ocorria o aumento do número de jovens de 15 a 24 anos na sociedade, eram afetados de maneira especialmente intensa em razão das profundas desigualdades econômicas e sociais, enfrentando dificuldades das mais diversas (ABAD, 2003).

E desta maneira, a condição juvenil refere-se principalmente ao modo como a sociedade organizada e atribui a definição a esse momento do ciclo da vida, especificando uma dimensão histórico-geracional, à medida em que a situação desses jovens evidencia o modo como tal etapa é vivida com base nos mais diferentes recortes - sociais, classe, gênero, etnia, entre outros (ABRAMO, 2008).

E, portanto, é nesse período, da juventude, que se inicia o processo de inserção nas diversas dimensões da idade adulta, como lembra Abramo (2014, p. 14) é "na constituição de famílias, no mundo do trabalho e nos espaços de cidadania. Assim sendo, na etapa da juventude se definem possibilidades e impossibilidades de inserção na vida produtiva e social, de desenvolvimento de projetos pessoais e sociais".

E por conta desse processo, utilizando-se dos ensinamentos de Abad (2003), a infância quase desapareceu, rodeada por uma adolescência que desabrocha muito cedo e uma juventude que se prolonga até depois dos 30 anos, o que acaba significando que quase 
um terço da vida e um terço da população tem esse rótulo, indeterminado e convencional como todos, porém simbolicamente intenso.

Onde, a juventude poderia ser enquadrada como um período de privações, com escassa autonomia e constantes constrangimentos pelas convenções sociais, sendo então caracterizada como uma etapa dura de aprendizagem das coisas para a vida, que todos deveriam passar com o intuito de adquirir suficiente experiência, normalmente de maneira penosa e árdua, antes de chegar à vida adulta (ABAD, 2003).

Contudo, como habitante de um mundo que encontra-se em constante transformação, a juventude atual vive problema e incerteza de seu tempo. Para Abramo (2014, p. 19, grifo original) essa juventude revela as "desigualdades econômicas, disparidades regionais, dicotomias entre campo e cidade, assim como preconceitos e discriminações (de gênero, raça-etnia, orientação sexual, religião, etc.)", que acabam afastando os jovens de classes e grupos sociais distintos.

E atrelado aos dias atuais, enquanto uma determinada parcela de crianças, adolescente e principalmente jovens se preparam para ingressar na vida adulta por intermédio da educação, outros buscam condições para que possam conciliar educação e trabalho. Porém, para todos está posta a questão da entrada e da permanência no mercado de trabalho, sendo este, cada vez mais caracterizado pela irregularidade, pela descontinuidade, pela precariedade de salário e por sua informalidade (ABRAMO, 2014).

Nessa situação, as políticas públicas tornaram-se ferramentas adequadas para a efetivação das ações políticas e desse modo a concretização de direitos fundamentais e sociais. Para tanto, imperioso que se faça uma abordagem, ainda que superficial, vez que esse estudo não esgota o assunto, dos conceitos metodológicos das políticas públicas.

Inicialmente, importa elucidar que a análise das políticas públicas não pode ser feita de maneira fragmentada e isolada, ela deve estar relacionada, especialmente, com as questões que permeiam o Estado e a sociedade, porquanto, segundo "elas são o resultado da política, compreensíveis à luz das instituições e dos processos políticos, os quais estão intimamente ligados às questões mais gerais da sociedade" (SCHMIDT, 2008, p. 2308). Assim, pode-se dizer que as políticas públicas são um conjunto de ações adotadas pelo governo, a fim de produzir efeitos específicos, ou de modo mais claro, a soma de atividades do governo que acabam influenciando a vida dos cidadãos.

E dessa maneira, seja pelo envolvimento de todos os membros da sociedade tanto na formulação quanto na avaliação das políticas públicas implementadas, ou ainda, seja pelo fato de centros de discussões e decisões para que se escolham ações específicas para Barbarói, Santa Cruz do Sul, Edição Especial n.44, p.<4-17>, jul./dez. 2015 
estas, com o principal objetivo de alcançar o desenvolvimento sustentável, deve-se buscar e ponderar os indicadores que se adaptem a partir de todos os resultados e objetivos pretendidos e que detenham as políticas públicas em sua instância viabilizadora (SILVA; SOUZA-LIMA, 2010).

E nesse contexto, um terreno ainda por ser efetivamente explorado é aquele no qual se encontra a análise das políticas públicas para a juventude, onde até o momento tem se situado no campo da ciência política, a qual prefere dar o enfoque a partir de seu aspecto técnico, isto é, o produto (policy) da atividade intermediário público, os denominados policy makers. E a partir do interesse constituído e do problema busca-se encontrar boas políticas ao mesmo tempo eficazes e eficientes com a finalidade de suavizar as arestas problemáticas da relação juventude versus sociedade adulta, para que juntas consigam diminuir as situações que podem acarretar a exclusão social (ABAD, 2003).

E por esse motivo, nas palavras de Silva e Souza-Lima (2010, p. 49) que tanto o processo de elaboração quanto o de implementação de uma política pública deve estar alinhavado com os objetivos e as finalidades que se pretendem alcançar, "com a realidade das pessoas que participam do processo amadurecimento e com a dimensão do desenvolvimento sustentável que se pretende atingir, possui caráter interdisciplinar”. Assim, as políticas públicas, são compreendidas como interdisciplinas no momento em que, de acordo com a sua diversidade e seus mais variados objetivos, podem alcançar dimensões distintas do desenvolvimento sustentável.

Portanto, analisando as políticas públicas com base em sua acepção mais genérica tem-se que se caracteriza pelo conjunto de ações articulados com recursos próprios, sejam eles financeiros ou humanos, envolvem uma dimensão temporal e uma capacidade de impacto. Onde, para Abad (2003) o termo pode ser compreendido a partir de sua dimensão ético-político da finalidade da ação, e deve se aliar, fundamentalmente a um projeto de desenvolvimento econômico-social e provocar maneiras de interação do Estado com a sociedade.

E a partir dessa concepção, busca-se a análise e elaboração de políticas públicas voltadas para a juventude, o que, tanto no Brasil quanto internacionalmente, é bastante recente. Contudo, como visto, o processo de transformação da tecnologia atrelado a intensificação dos mercados em uma era globalizada, fez emergir, na concepção de Abramo (2014), uma nova divisão internacional do trabalho evidenciando situações de pobreza e precarização das relações, onde tais mudanças sociais, incluindo aquelas que as acompanharam, atingem diretamente a juventude.

Barbarói, Santa Cruz do Sul, Edição Especial n.44, p.<4-17>, jul./dez. 2015 
E deste modo, diante da atual crise mundial, bancos, governos e organismos internacionais buscam ao mesmo tempo sair do colapso e superar a pobreza instalada discutindo os problemas da juventude. Uma vez que, a fragilidade do atual modelo econômico foi revelada, colocando-se a necessidade de se pensar políticas públicas de e para a juventude.

E neste contexto de políticas públicas está a finalidade extrafiscal da norma tributária, enquanto propagador do desenvolvimento social atrelado a atenção à juventude. Assunto este, tratado na sequência.

\section{A finalidade extrafiscal da norma tributária como mecanismo de implementação de políticas públicas}

O conceito jurídico para o ordenamento brasileiro de tributos está elencado no artigo terceiro do Código Tributário Nacional, cujos termos estabelecem como sendo "toda prestação pecuniária compulsória, em moeda ou cujo valor nela se possa exprimir, que não constitua sanção de ato ilícito, instituída em lei e cobrada mediante atividade administrativa plenamente vinculada”. Sendo assim, na definição de Ataliba (1997), apresenta-se como uma obrigação jurídica pecuniária, onde o sujeito ativo é uma pessoa pública, podendo ocorrer à delegação, e o sujeito passivo qualquer indivíduo que a legislação assim o caracterizou.

Nesse sentido, compreender o tributo como o meio de obtenção de receita para o Estado importa referir à finalidade mais basilar do direito tributário que neste caso é a finalidade fiscal. Deste modo, a fiscalidade consiste na utilização de mecanismos para "prover o caixa do Estado (entes federados) de recursos, destinados a fazer frente às despesas estatais. O conceito é simples e geral e vale tanto para o direito tributário quanto para o direito financeiro" (GOUVÊA, 2006, p. 175, grifo original).

Portanto, o tributo tem como principal objetivo arrecadar recursos para que consiga suprir as necessidades dos cofres públicos decorrendo da supremacia do interesse público em detrimento do interesse particular, isto é, no entendimento de Balthazar (1999) a finalidade fiscal do tributo enquadra-se na arrecadação de receita visando à satisfação das necessidades públicas.

Contudo, o tributo pode ser compreendido a partir de suas outras finalidades, como é o caso da extrafiscalidade, onde não almeja prioritariamente a arrecadação de valores para o Estado, pelo contrário, visa "ordenar a propriedade de acordo com a sua função Barbarói, Santa Cruz do Sul, Edição Especial n.44, p.<4-17>, jul./dez. 2015 
social ou a intervir em dados conjunturais (injetando ou absorvendo a moeda em circulação) ou estruturais da economia" (DERZI, 1999, p. 233). Deste modo, a função extrafiscal busca estimular ou desestimular determinados comportamentos por intermédio da tributação progressiva ou regressivo, ou ainda, da concessão de benefícios e incentivos fiscais.

Assim sendo, essa finalidade do tributo força o cidadão a obtenção de comportamentos com o objetivo de se alcançar um determinado fim onde, para Mattos (2012) o interesse púbico deve-se sempre sobrepor sobre o interesse particular.

Sempre que os interesses da comunidade como um todo estejam em discussão,
os interesses particulares deverão ceder espaço a fim de que os primeiros sejam
preservados, e, com isto, a segurança como um todo seja resguardada. Assim, por
exemplo, o combate ao desemprego, ou a preservação do nível do emprego a
utilização racional da propriedade a fim de que a mesma cumpra com sua função
social, a preservação do meio ambiente e de condições fitossanitárias mínimas
para a sobrevivência do homem [...] (BERTI, 2009, p. 41).

Neste contexto, a indução por parte do Estado de determinados comportamentos mediante vantagem fiscal será exercido sobre aqueles que se enquadrarem nos requisitos legais, se a isenção for individual, podendo ser geral em isenções de caráter universal. Interessante os ensinamentos de Silva (2007, p. 117), quando afirma que uma isenção geral pode vir acompanhada de carga extrafiscal, onde, por exemplo, se direciona “objetivamente, à produção do álcool combustível, estimula seu consumo em prejuízo do consumo de gasolina". Ou também quando se direciona, "subjetivamente, aos fabricantes de malhas têxteis, favorece o aparecimento de indústrias desse tipo de vestuário em detrimento dos curtumes".

Destarte, importante lembrar que a isenções fiscais, a partir de seu efeito extrafiscal, pode ser no âmbito de uma determinada região do país ou do estado, onde se busca um objetivo específico como pode ser irrestrito territorialmente, quando os efeitos dessa extrafiscalidade poderão ser observados em toda a extensão do território.

E diante desse cenário, tem-se como objeto desse estudo a finalidade extrafiscal da norma tributária como mecanismo de implementação de políticas públicas, onde, de acordo com Schoueri (2005) essa utilização do tributo é fruto de uma evolução que já se verifica em outros ordenamentos jurídicos, quando se propõem a intervir de forma ativa no campo socioeconômico com a finalidade de tutela, de redistribuição e de equilíbrio das relações sociais. À vista disso, diante do Estado moderno, além das finanças públicas serem um meio de assegurar a cobertura de despesas administrativas, podem principalmente 
intervir e de certa maneira regular a vida social, realizando influência sobre os cidadãos para organizar o conjunto da nação.

Todavia, a aplicação da extrafiscalidade em nome do interesse coletivo não necessita estar atrelada a perda de numerário, quando do aumento ou diminuição de alíquotas ou bases de cálculos, como ensino Martins (2009), ao exemplificar esse processo quando ocorre a exacerbação da tributação sobre o consumo de cigarros, podendo, além de desestimular o consumo, aumentar a arrecadação.

Neste sentido, toda e qualquer finalidade tributária não arrecadatória enquadrarse-á como conotação extrafiscal. O que não excluirá a sua função fiscal, podendo ambos conviver de forma harmônica no ordenamento tributário, ocorrendo somente, segundo Martuscelli (2001), a não exclusividade de um fim, mas sim a preponderância de um determinado fim sobre o outro, neste caso, a extrafiscalidade sobre a fiscalidade.

Com isso se quer dizer, pragmaticamente, que dentre as ferramentas que o Estado se vale para intervir no campo socioeconômico - almejando promover a justiça social, com regulação do mercado, redistribuição de riqueza, equilíbrio da balança, inclusão social etc. - está o direito tributário, que disponibiliza através da função extrafiscal do tributo que se façam políticas públicas com a utilização das normas tributárias (MARTINS, 2009, p. 101, grifo original).

Portanto, a promoção de políticas públicas a partir da utilização da tributação extrafiscal tem por finalidade a redistribuição de renda e de terras, a defesa da indústria nacional, a orientação de certos investimentos em setores estratégicos de produção, mas, principalmente no incentivo a jovens que carecem de ações efetivas de cidadania que, por diferentes fatores, foram excluídos do processo educacional, de modo a reduzir situações de risco, desigualdade, discriminação e outras vulnerabilidades sociais, fomentando a participação social e cidadã desses jovens.

Nesse contexto, Silva (2007, p. 100) lembra que o valor finalístico da extrafiscalidade que atribui o legislador a norma tributária, deve atender ademais da condução econômica, a correção de situações econômicas indesejadas, podendo inclusive fomentar "certas atividades ou ramo de atividades de acordo com os preceitos constitucionais ${ }^{1}$,

\footnotetext{
${ }^{1}$ Art. 227. É dever da família, da sociedade e do Estado assegurar à criança, ao adolescente e ao jovem, com absoluta prioridade, o direito à vida, à saúde, à alimentação, à educação, ao lazer, à profissionalização, à cultura, à dignidade, ao respeito, à liberdade e à convivência familiar e comunitária, além de colocá-los a salvo de toda forma de negligência, discriminação, exploração, violência, crueldade e opressão. § $8^{\circ} \mathrm{A}$ lei estabelecerá: I - o estatuto da juventude, destinado a regular os direitos dos jovens; II - o plano nacional de Barbarói, Santa Cruz do Sul, Edição Especial n.44, p.<4-17>, jul./dez. 2015
} 
Sendo assim, toda a atividade legislativa e executiva deve ser orientada buscando o interesse social, sendo este um objetivo claro, que decorre da natureza prática das coisas em harmonia com o convivo social. E de igual maneira, a extrafiscalidade tributária exerce um papel de destaque na elaboração e aplicação de políticas públicas de desenvolvimento e inclusão social de jovens diante do atual cenário, sendo este, assunto do próximo capítulo.

\section{A extrafiscalidade tributária enquanto política pública de desenvolvimento e de inclusão social de jovens}

Como visto, a Constituição da República Federativa do Brasil de 1988 adotou a extrafiscalidade como um procedimento comum do direito tributário, principalmente como ferramenta de implementação de políticas públicas ao autorizar a exacerbação ou suavização do ônus fiscal. Como lembra Machado (1997) que inicialmente o objetivo do tributo para a arrecadação de valores ao Estado, contudo, diante de um mundo moderno, o tributo passou a ser compreendido como uma medida eficaz de intervenção na economia, estimulação de atividades, setores, desestimulando o consumo de determinados bens e dessa forma produzindo os mais variados efeitos na sociedade.

E, portanto, os principais mais basilares do direito trazidos pela Constituição, tais como a segurança jurídica, a justiça social e o bem comum, ligados diretamente com a efetivação dos direitos fundamentais, fazem-se presente principalmente na imunidade, isenção e benefícios fiscais, cuja sua natureza é extrafiscal.

Neste contexto, de acordo com Martins (2009) no arcabouço da extrafiscalidade estão previstas as condutas desejadas, aquelas que devem ser estimuladas, mas também estão as condutas indesejadas, que devem ser desestimuladas pelo legislador. Entretanto, não estão compreendidas as condutas contrárias ao ordenamento jurídico, tidas como proibidas, e que via de regra essas são alvo das sanções negativas (penalidades). A exemplo, quando da aplicação de multa por descumprimento de obrigação fiscal, o Estado exerce o controle social tradicional, guiado pela faculdade do ordenamento de caráter repressiva (coatora).

É diante desse contexto de função extrafiscal do tributo que Bonavides (1998) convida a todos para rever suas posições conservadoras e redesenhar as instituições e

juventude, de duração decenal, visando à articulação das várias esferas do poder público para a execução de políticas públicas. (BRASIL. Constituição da República de 1988, 1998, grifo próprio).

Barbarói, Santa Cruz do Sul, Edição Especial n.44, p.<4-17>, jul./dez. 2015 
aplicações do Estado com base nas necessidades de um mundo contemporâneo. Dessa forma, deve buscar a imaginação coletiva das sociedades, refutando o racionalismo dos publicistas que encarcera as instituições no imobilismo e na repetição, "como se já houvesse no quadro dos conceitos e das fórmulas sobejamente conhecidas uma resposta adequada a cada problema ou a cada desafio que surgisse" (BONAVIDES, 1998, p. 218).

Portanto, a reformulação do pensamento atual deve ser pautada pela busca uma política pública fiscal que tenha por finalidade a contemplação dos interesses públicos voltados efetivamente a coletiva, sendo este um processo público com a participação de todos os interessados, para que juntos possam objetivar a justiça social de fato.

Sendo assim, a elaboração, implementação e execução de políticas públicas devem ter como prioridade estratégias para o alcance de melhores condições de vida para o indivíduo e a sociedade. De tal modo, segundo Silva e Souza-Lima (2010), as políticas devem ter parâmetros determinados de mensuração, para que viabilize o acompanhamento no decorrer do percurso, podendo assim amadurecer sustentavelmente e expressar de forma contundente indicadores de sua efetividade.

Nessa conjuntura, as políticas públicas tornaram-se ferramentas adequadas para a efetivação das ações políticas e desse modo a concretização de direitos fundamentais e sociais. Para tanto, imperioso que se faça uma abordagem, ainda que superficial, vez que esse estudo não esgota o assunto, dos conceitos metodológicos das políticas públicas. Em vista disso, a análise das políticas públicas tem desempenhado importante papel no aperfeiçoamento da compreensão do funcionamento das instituições públicas, principalmente nos tempos atuais. Desse modo, Schmidt (2008, p. 2330) afirma que "investigando os resultados, as políticas (policies) entende-se melhor os processos (politics) e o aparato institucional (polity) da política”.

Nesse cenário, uma maneira de avaliar a efetivação de uma determinada política púbica, podendo ser a partir da função extrafiscal do tributo, é por meio do desenvolvimento e aplicação do IDH (Índice de Desenvolvimento Humano) e do IDH-M (Índice de Desenvolvimento Humano Municipal), onde diversos estudos publicados no Brasil possibilitaram uma aproximação no que se refere a compreensão e a utilização do índice por toda a sociedade, até mesmo no desenvolvimento de políticas públicas. Sendo assim, esses índices possibilitaram "uma avaliação mais abrangente do nível de desenvolvimento humano do País e das precárias condições sociais que afligem boa parte da população, principalmente nas regiões menos desenvolvidas" (SILVA; SOUZA-LIMA, 2010, p. 152).

Barbarói, Santa Cruz do Sul, Edição Especial n.44, p.<4-17>, jul./dez. 2015 
E assim, as políticas públicas podem ser compreendidas como o resultado da política, das instituições e até mesmo de seus procedimentos. Dessa forma, quem estabelece o desmembramento entre esta e aquelas ignora a essência de ambas. Onde "a abordagem sistêmica, aqui apresentada, tem o grande mérito de evidenciar os estreitos liames das políticas com o conjunto dos componentes de um sistema político (instituições, processos, atores, arenas, lideranças, cultura política)" (SCHMIDT, 2008, p. 2330, grifo original).

E diante desse ambiente de inclusão social de indivíduos excluídos, tem-se uma parcela da juventude brasileira que se vê a margem do sistema de proteção dos direitos fundamentais. Esse fenômeno reflete o esgotamento do modelo desenvolvimentista como afirma Abramo (2014), onde as reformas de caráter social com cunho liberal questionaram os direitos sociais até então consagrados. E a partir disso, enfraqueceram os instrumentos corporativistas fundados na solidariedade e no fortalecimento de critérios ligados com a competição no mercado e à individualização dos riscos.

Portanto, a implementação de políticas públicas com base na função extrafiscal da norma tributária reflete em toda a fundamentação do Estado Contemporâneo, uma vez que surge como um mecanismo institucional legítimo de formulação, mecanização e implementação para que uma política pública possa ser enquadrada como viável. Corroborando com esse entendimento, Silva (2007, p. 119) relembra que a "finalidade extrafiscal da norma tributária constitui-se na aplicação de um modelo jurídico-tributário para a consecução de objetivos que preponderam sobre os fins simplesmente arrecadatórios de recursos financeiros para o Estado".

E nesse contexto, incumbe a lei tributária atender as necessidades da sociedade por meio da finalidade extrafiscal, ao ordenar a condução da economia, corrigir determinadas situações sociais que desejadas ou até mesmo possibilitar a promoção de ramos de atividades consoantes com os preceitos constitucionais. De natureza idêntica, o Estado comprometido com as suas finalidades sociais exercita, no entendimento de Martins (2009), seu papel enquanto agente transformador da realidade social, utilizando-se para isso políticas públicas para a juventude.

Consequentemente, busca-se a construção de uma outra globalização, na qual seja menos excludente. Uma globalização que traga/comporta esperança àqueles em que ela não se evidencia como elemento de uma realidade inclusiva. Uma globalização, a partir de uma nova racionalidade, de um pensamento convergente na construção de um universalismo que contemple a todos iguais condições/possibilidades (SANTOS, 2001). 
E a partir disso, na concepção de Martins (2009) surge a compreensão de que o ordenamento jurídico pode desempenhar um papel fundamental na maneira de cooperação e compartilhamento das responsabilidades sociais, essencialmente na promoção de comportamentos sociais desejados por meio da função extrafiscal do tributo. E neste ambiente, no Brasil, mais precisamente em agosto de 2013, a juventude pode reacender a chama da esperança, com a edição do Estatuto da Juventude que prevê que direitos já elencados possam ser aprofundamentos e efetivamente garantidos atendendo as necessidades específicas dos jovens, respeitando assim a sua trajetória e diversidade.

\section{Considerações finais}

Por essas razões que o Estado, enquanto agente promotor e difusor de direitos e garantias fundamentais se apresenta como um dos responsáveis diretos pela concretização dos direitos da juventude. E essa atuação é objetivada por meio das políticas públicas, tornando-se evidente que essas devem ser formuladas e implementadas de maneira a promover de forma efetiva os direitos e garantias de jovens.

Diante dessa perspectiva, a implementação de políticas públicas baseadas na função extrafiscal do tributo, tem como propriedade a correção de externalidades, sejam elas positivas ou negativas. Podendo ter sua finalidade aplicada à juventude, quando, por exemplo, incentiva a geração de empregos ou quando utilizada como mecanismo viabilizador do ingresso de estudantes carentes no ensino superior, com a finalidade de organizar a vida em sociedade e a nivelação dos tipos e modos de viver.

Deste modo, as ações do poder público devem ser focadas no cidadão e no bemestar da coletividade, por isso que a participação cidadã se torna relevante. Ninguém melhor que os legítimos detentores da soberania - o povo - para promover processos dinâmicos de discussões e debates sobre suas demandas, a fim de levá-las ao governo para a sua efetivação, e de plano de fundo, promover-se na prática a garantia de uma série de direitos da juventude.

Portanto, não se pode combater problemas oriundos do processo da globalização e de exclusão com programas assistencialistas, dado que, quando esses programas forem interrompidos, pelos mais diversos fatores, necessitados continuarão a sofrer. À vista disso, deve-se buscar a implementação de políticas públicas com base na extrafiscalidade da norma tributária como fomentador da economia, qualificação da educação para crianças e a geração de oportunidades de empregos para a nossa juventude.

Barbarói, Santa Cruz do Sul, Edição Especial n.44, p.<4-17>, jul./dez. 2015 


\section{Referências}

ABAD, Miguel. Crítica política das políticas de juventude. In: PAPA, F. C.; FREITAS, M. V. (Orgs.). Políticas Públicas: Juventude em pauta. São Paulo: Cortez: Ação Educativa Assessoria, Pesquisa e Informação: Fundação Friedrich Ebert, 2003.

ABRAMO, Helena. Secretaria Nacional de Juventude. Estação juventude: conceitos fundamentais - ponto de partida para uma reflexão sobre políticas públicas de juventude. Brasília: SNJ, 2014.

Considerações sobre a tematização social da juventude no Brasil. Revista Brasileira de Educação, São Paulo, ANPED n. 5-6, 1997, p. 25-36.

ATALIBA, Geraldo. Hipótese de incidência tributária. São Paulo: Malheiros, 1997.

BALTHAZAR, Ubaldo Cesar. Manual de direito tributário. Florianópolis: Diploma Legal, 1999.

BERTI, Flávio de Azambuja. Impostos, extrafiscalidade e não confisco. 3. ed. Curitiba: Juruá, 2009.

BONAVIDES, Paulo. Reflexões: política e direito. 3. ed. São Paulo: Malheiros, 1998.

BOURDIEU, Pierre. Questões de Sociologia. Rio de Janeiro, Marco Zero, 2005.

GOUVÊA, Marcus de Freitas. A extrafiscalidade no direito tributário. Belo Horizonte: Del Rey, 2006.

MACHADO, Hugo de Brito. Curso de direito tributário. São Paulo: Malheiros, 1997.

MARTINS, Vinicius Malta. A função promocional do direito tributário na extrafiscalidade por estímulos: o direito como indutor de uma cidadania ativa e participante. 2009. 139 f. Dissertação (Programa de Pós-Graduação em Direito Mestrado e Doutorado)-Universidade de Santa Cruz do Sul, Santa Cruz do Sul, 2009.

MARTUSCELLI, Fernando José Dutra. Elementos de direito tributário. Campinas: Bookseller, 2001.

MATTOS, Fabiana Eliza. A extrafiscalidade tributária como forma de implementação da justiça social. 2012. 103 f. Dissertação (Programa de Pós-Graduação em Direito Mestrado e Doutorado)-Universidade de Santa Cruz do Sul, Santa Cruz do Sul, 2012.

MORAES, Antônio Ermírio de. Somos todos responsáveis: De que tipo de juventude o Brasil precisa? De que tipo de país a juventude precisa? São Paulo: Gente, 2007.

OLIVEIRA, José Domingues de. Direito tributário e meio ambiente: proporcionalidade, tipicidade aberta, afetação da receita. 2. ed. Rio de Janeiro: Renovar, 1999.

RIZZINI, Irene. O século perdido: raízes históricas das políticas públicas para a infância no Brasil. 3. ed. São Paulo: Cortez, 2011. 
SANTOS, Milton. Por uma outra globalização: do pensamento único à consciência universal. 6. ed. Rio de Janeiro: Record, 2001.

SCHMIDT, João Pedro. Para entender Políticas Públicas: aspectos conceituais e metodológicos. In: REIS, J. R.; LEAL, R.G. (Orgs.). Direitos Sociais e Políticas Públicas: desafios contemporâneos. Tomo 8. Santa Cruz do Sul: EDUNISC, 2008, p. 2307-2333.

SCHOUERI, Luís Eduardo. Normas tributárias indutoras e intervenção econômica. Rio de Janeiro: Forense, 2005.

SILVA, C. L.; SOUZA-LIMA, J. E. Políticas Públicas e indicadores para o desenvolvimento sustentável. São Paulo: Saraiva, 2010.

SILVA, Daniel Cavalcanti. A finalidade extrafiscal do tributo e as políticas públicas no Brasil. Revista Primas: Direito, políticas públicas e mundialização. Brasília, v.4, n, 1, p. 98-122, jan/jul. 2007.

\section{Sobre os autores:}

Fabiano Rodrigo Dupont é Mestrando em Direito na Universidade de Santa Cruz do Sul/RS UNISC, na linha de pesquisa Políticas Públicas. Graduado em Direito pela Universidade de Santa Cruz do Sul - UNISC (2013). Integrante dos grupos de pesquisa: Gestão Local e Políticas Públicas - coordenado pelo Prof. Pós-Dr. Ricardo Hermany; Políticas Públicas junto a Escola Miguel Arraes / Fundação João Mangabeira - DF. Integrante do Projeto de Pesquisa intitulado: Relação entre o Estado e a Sociedade Civil na formação profissional dos jovens objetivando a diminuição da criminalidade: Uma análise sob a perspectiva da gestão pública compartida. Endereço eletrônico: fabianodupont@ hotmail.com

Rodrigo Cristiano Diehl é Pós-Graduando (lato sensu) em Direito Constitucional e Administrativo pela Escola Paulista de Direito. Acadêmico do curso de Direito da Universidade de Santa Cruz do Sul - UNISC. Integrante dos grupos de pesquisa "Direito, Cidadania e Políticas Públicas" (campus Santa Cruz do Sul - RS e campus Sobradinho RS), coordenado pela Pós-Dra. Marli Marlene Moraes da Costa; "Direitos Humanos", coordenado pelo Pós-Dr. Clovis Gorczevski; e "A Decisão Jurídica a partir do Normativismo e suas Interlocuções Críticas", coordenado pela Dra. Caroline Muller Bitencourt, ambos do Programa de Pós-Graduação em Direito - Mestrado e Doutorado da UNISC e certificados pelo CNPq. Atualmente é bolsista de Iniciação Científica da Fundação de Amparo à Pesquisa do Estado do Rio Grande do Sul - FAPERGS (Edital 2013-2015), coordenado pela Pós-Dra. Marli Marlene Moraes da Costa. Autor de diversos artigos científicos publicados em revistas, livros e eventos internacionais. Endereço eletrônico: rodrigocristianodiehl@live.com 